09

\title{
Голографический метод количественного измерения фотолитографических реплик толстых рельефных дефектов поверхности
}

\author{
(C) Н.С. Будников ${ }^{1}$, В.В. Дуденкова ${ }^{1}$, В.Е. Котомина ${ }^{1}$, \\ О.А. Морозов ${ }^{1}$, В.В. Семенов ${ }^{2}$ \\ ${ }^{1}$ Нижегородский государственный университет им. Н.И. Лобачевского, \\ Нижний Новгород \\ ${ }^{2}$ Институт металлоорганической химии им. Г.А. Разуваева РАН, Нижний \\ Новгород \\ E-mail: orannge@mail.ru
}

Поступило в Редакцию 20 января 2017 г.

Для задачи оценки характерных размеров и рельефа микродефектов поверхности образцов сложной формы представлен голографический метод измерений прозрачных реплик - обратной маски к исследуемой поверхности. Метод измерений основан на цифровой регистрации интерферограмм полимерной реплики в модифицированной внеосевой голографической схеме Лейта-Упатниекса и расчете разности набега фазы по серии восстановленных цифровых голограмм.

DOI: 10.21883/PJTF.2017.11.44700.16710

Для оценки характеристик состояния поверхности материалов с линейным размером порядка или более $1 \mathrm{~mm}$ обычно используются оптико-телевизионные измерительные системы, реализующие методы обработки оптических изображений и спекл-интерферометрии $[1,2]$. Для прецизионного изучения деформированного состояния поверхности материалов с высоким пространственным разрешением (порядка $10-100 \mathrm{~nm}$ ) может быть использовано специализированное оборудование, позволяющее регистрировать профиль поверхности, в частности сканирующие зондовые микроскопы, и соответствующие алгоритмы обработки регистрируемых данных $[3,4]$.

Выявление и визуализация дефектов поверхности с линейными размерами порядка $1-100 \mu \mathrm{m}$ с их дальнейшей количественной оценкой с 


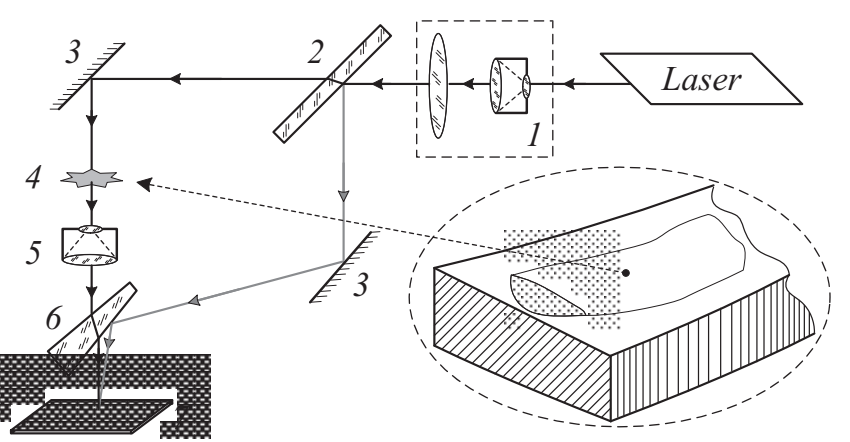

Рис. 1. Принципиальная оптическая схема внеосевой голографии прозрачных реплик объектов с возможностью цифровой регистрации.

высоким пространственным разрешением является актуальной задачей в сфере микроанализа износа и качества поверхностей. Ряд факторов существенно ограничивает возможности применения традиционной для данной задачи аппаратуры - оптических или конфокальных сканирующих микроскопов, контактных и лазерных профилометров. К таким факторам можно отнести относительно широкий диапазон линейных размеров изучаемых структур при необходимом пространственном разрешении менее $1 \mu \mathrm{m}$ и сложную геометрию исследуемых образцов. Характерным примером может служить задача визуализации и измерения формы и размеров дефектов поверхности материала втулок, держателей, валов и т.д.

Для решения задачи получения информации о дефектных областях и оценки характерных размеров дефектов в работе предлагается использовать метод репликации. Реплики изготавливались методом фотолитографии на участке поверхности исследуемого образца (рис. 1) с использованием фотополимеризующихся при действии ультрафиолетового света негативных прозрачных в оптическом диапазоне полимерных композиций. В работе использовалась жидкая фотополимеризующаяся композиция (ФПК) „ТИОЛ“, разработанная Нижегородским предприятием „Репер-НН“ и состоящая из олигоэпоксидиакрилата ЭАС-20M (45 mass\%) и бензилметакрилата (БМА) (55 mass \%) [5]. Фотоинициатором служил 2,2-диметокси-2-фенилацетофенон (ДМФАФ), концентрация в смеси $0.03 \mathrm{~mol} / 1$. Для визуализации дефектов образца,

Письма в ЖТФ, 2017, том 43, вып. 11 
зафиксированных на реплике, и последующих измерений использовался метод регистрации разности набега фазы в модифицированной внеосевой голографической схеме Лейта-Упатниекса (выбрана оптическая схема, предназначенная для регистрации на прохождение) с цифровой регистрацией голографического изображения [6].

В нашем случае ФПК использовалась для получения своеобразной обратной маски к исследуемой поверхности, т.е. для получения негативного оттиска нужного фрагмента образца для дальнейшего исследования с помощью оптической микроскопии, растровой электронной микроскопии и оптической интерферометрии. На предварительно подготовленную (очищенную ацетоном ОСЧ) поверхность образца тонким слоем наливался фотополимер таким образом, чтобы все микрополости были заполнены. Наиболее оптимальные образцы для последующего экспонирования получались с толщинами от 1 до $2.5 \mathrm{~mm}$. В более толстых образцах после экспонирования наблюдались воздушные микрополости, которые негативно влияют на последующую обработку данных.

Экспонирование производилось действием УФ-света с длиной волны $\lambda=350-420 \mathrm{~nm}$ на установке совмещения и экспонирования ЭМ-5026М1. Время экспозиции для разных толщин образцов подбиралось экспериментально, так как процесс полимеризации проходит послойно. Время экспозиции для толщин от 1 до $2.5 \mathrm{~mm}$ составляло соответственно от 120 до $180 \mathrm{~s}$ в зависимости от толщины маскирующего слоя. Для предотвращения ингибирующего воздействия кислорода на процесс полимеризации композиция на время экспонирования закрывалась лавсановой пленкой. После прохождения фотополимеризации проводилось термоотверждение в конвекционном шкафу с аналогичным подбором времен выдержки образцов с различной толщиной. Время выдержки при температуре $90^{\circ} \mathrm{C}$ в конвекционном шкафу составляло 40-60 min в зависимости от толщины полимерного оттиска образца. Контроль полученных образцов осуществлялся при помощи оптического микроскопа LeicaDM-4000 и заключался в установлении качества оттиска, проверке на отсутствие воздушных микрополостей в приготовленном образце.

Полученные оттиски исследовались на оригинальной цифровой внеосевой голографической схеме с целью установления фазового набега и его численной интерпретации. Используемая голографическая схема (рис. 1) основана на схеме Лейта-Упатниекса, где сформированный

$6^{*}$ Письма в ЖТФ, 2017, том 43, вып. 11 

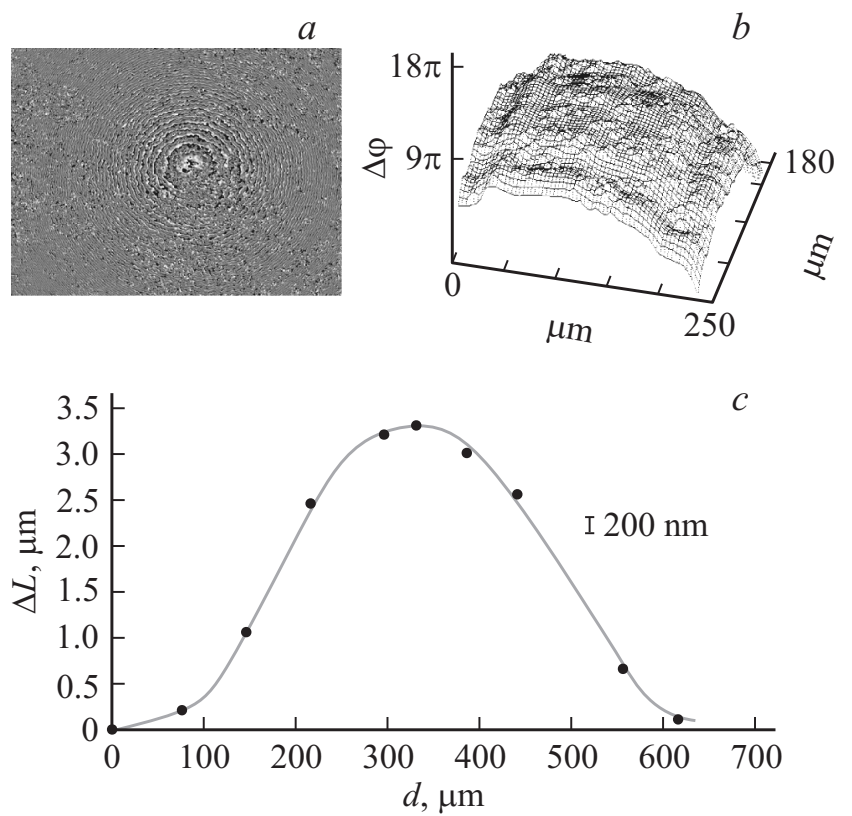

Рис. 2. Результаты обработки цифровой голограммы: $a$ - восстановленное распределение фазы; $b$ - трехмерное распределение набега фазы (оптическая длина) центральной части отпечатка; $c$ - профиль центрального поперечного сечения отпечатка.

системой 1 микрообъектив - линза луч лазера разделяется светоделительной пластинкой 2 на предметный и опорный лучи. Предметный луч проходит через исследуемый объект 4 , и с помощью объектива 5 строится его увеличенное изображение в плоскости регистрирующей фотоэлектрической матрицы 7. Опорный луч после светоделительной пластинки направляется зеркалом 3 на полупрозрачное зеркало 6 , с помощью которого совмещаются опорный и предметный лучи, образуя угол сходимости, необходимый для разделения порядков восстановленного изображения. Интерференционная картина в плоскости регистрации оцифровывается матрицей, формируя соответственно цифровую голограмму. Отличительной особенностью данной схемы является то, что из-за микроскопических размеров изменений, наблюдаемых на 
объекте, применяется увеличивающий объектив (используется объектив Zeiss ACHROPLAN 40x/0.8), что позволяет снизить максимальные пространственные частоты и компенсировать низкую для голографии разрешающую способность цифровых матриц.

Для получения оптической толщины объекта необходимо вычислить разность фаз волн, восстановленных из голограмм, полученных при одних и тех же условиях: из голограммы объекта и из голограммы, полученной той же схемой без объекта и содержащей все фазовые набеги и амплитудные искажения, вносимые схемой. Таким образом, цифровая интерферометрия устраняет помехи, вносимые элементами оптической схемы. Для восстановления голограмм сфокусированного изображения в цифровой голографии применяют алгоритмы, основанные на использовании прямого и обратного преобразований Фурье с фильтрацией в частотной плоскости. Для реконструкции фазового набега используется вычисление разности фаз комплексных амплитуд волн, прошедших через объект в двух сравниваемых состояниях [6]:

$$
\begin{aligned}
\Delta \phi & =\operatorname{arctg}\left[\operatorname{tg}\left(\phi_{1}-\phi_{2}\right)\right]=\operatorname{arctg}\left[\frac{\operatorname{tg} \phi_{1}-\operatorname{tg} \phi_{2}}{1+\operatorname{tg} \phi_{1} \operatorname{tg} \phi_{2}}\right] \\
& =\operatorname{arctg}\left[\frac{\operatorname{Im}\left(A_{1}\right) \operatorname{Re}\left(A_{2}\right)-\operatorname{Im}\left(A_{2}\right) \operatorname{Re}\left(A_{1}\right)}{\operatorname{Re}\left(A_{1}\right) \operatorname{Re}\left(A_{2}\right)+\operatorname{Im}\left(A_{1}\right) \operatorname{Im}\left(A_{2}\right)}\right],
\end{aligned}
$$

где комплексные амплитуды восстановленных объектных волн $A_{1}$ и $A_{2}$ вычисляются непосредственно из данных, полученных восстановлением цифровых голограмм, а устранение неоднозначности арктангенса проводится алгоритмом разворачивания фазы $[7,8]$ (добавлением или вычитанием $\pi k$ ).

На рис. 2, $a, b$ приведены результаты обработки цифровой голограммы реплики объекта, соответствующие центру отпечатка. Область дефекта представляет собой след от сферического индентора после приложения нагрузки, размер поля зрения $2140 \times 1600$ пикселей, что соответствует размеру $250 \times 187 \mu \mathrm{m}$. После выполнения преобразования Фурье по интенсивности спектра определяется расположение порядков дифракции, выделяется область порядка дифракции, с которого производится восстановление распределения комплексной амплитуды и фазы записанного участка. Восстановление глубины изменения профиля (оп-

Письма в ЖТФ, 2017, том 43, вып. 11 
тической длины пути) поверхности производится на основе выражения

$$
\Delta L_{o p t}=\frac{\Delta \phi \lambda}{2 \pi}
$$

c учетом гомогенности распределения коэффициента преломления в образце полимера получаем, что при набеге фазы $\Delta \varphi=3.5 \pi$ и длине волны зондирующего излучения $\lambda=633 \mathrm{~nm}$ длина оптического пути $\Delta L_{\text {opt }}$ будет порядка $1 \mu \mathrm{m}$, а для получения реальных глубин результаты необходимо разделить на коэффициент преломления материала реплики $k \approx 1.6$.

Восстановленный по набору голограмм соседних областей профиль („оптическая высота“) отпечатка представлен на рис. 2,c, рассчитанная глубина профиля отпечатка составляет $3.3 \mu \mathrm{m}$. Контроль точности проведения измерений может быть выполнен различными способами. Так, в нашем случае на объекте хорошо видны царапины в виде линейных продолжительных возвышений. Проведенные измерения на участке реплики, содержащем только отпечатки царапин, дают средний размер оптической высоты дефектов порядка $0.3 \mu \mathrm{m}$, что хорошо согласуется с измерениями, выполненными на изначальном образце на сканирующем зондовом микроскопе. Кроме того, проведена регистрация серии изображений, представляющих собой распределение сигнала отражения от поверхности образца, на инвертированном конфокальном лазерно-сканирующем микроскопе LSM 710 (Carl Zeiss) с шагом по глубине $0.47 \mu \mathrm{m}$. На полученных изображениях было хорошо видно изменение кривизны дуги сечения визуализируемого дефекта в каждой следующей фокальной плоскости, что, с учетом сферической геометрии исследуемого дефекта образца, позволило оценить зависимость изменения радиусов сечения с высотой фокальной плоскости, характеризующую профиль высоты (глубины) дефекта, и характерный размер вмятины. Рассчитанная глубина отпечатка составила $3.4 \mu \mathrm{m}$.

Таким образом, голографический метод измерения профиля высоты дефектов, основанный на получении прозрачных реплик с поверхности объекта сложной формы, с последующей цифровой регистрацией и вычислением набега фазы по восстановленной цифровой голограмме, дает адекватные, сравнимые с другими методами исследования результаты. Можно также отметить, что данный метод позволяет преодолеть ряд трудностей, связанных с интерпретацией результатов измерений, в частности, наклон и расположение образца не влияют 
на фактическую толщину объекта при вычислении набега фазы путем восстановления цифровых голограмм, что устраняет неоднозначность определения глубины, связанную с наклоном образца.

\section{Список литературы}

[1] Экспериментальная механика: в 2т. / Под ред. А. Кобаяси. М.: Мир, 1990.

[2] Панин В.Е., Егорушкин В.Е., Макаров П.В. и др. Физическая мезомеханика и компьютерное конструирование материалов. Новосибирск: Наука, 1995. T. $1.298 \mathrm{c}$.

[3] Минеев С.А., Морозов О.А., Сотникова О.В., Гущина Ю.Ю. // Поверхность. Рентгеновские, синхротронные и нейтронные исследования. 2000. № 7. C. $96-98$.

[4] Семенова О.В., Зашивалова И.А., Морозов О.А. // Письма в ЖТФ. 2008. T. 34. B. 14. C. 32-39.

[5] Treushnikov V.M., Chesnokov S.A. // J. Photochem. Photobiol. A. Chem. 2008. V. 196. N 2-3. P. 201-209.

[6] Муравьева М.С., Дуденкова В.В., Рыбников А.И., Захаров Ю.Н. // Известия вузов. Радиофизика. 2014. Т. 57. № 8-9. С. 646-653.

[7] Рыбников А.И., Дуденкова В.В., Муравьева М.С., Захаров Ю.Н. // Оптический журнал. 2013. Т. 80. № 7. С. 66-73.

[8] Рореscu G. Quantitative phase imaging of cells and tissues. McGraw-Hill Companies, Inc., 2011. 362 p.

Письма в ЖТФ, 2017, том 43, вып. 11 